\title{
Criação de aplicativo móvel para enfermagem oncológica: uma análise de conteúdo
}

\author{
Creation of mobile application for oncology nursing: a content analysis \\ Creación de una aplicación móvil para enfermería oncológica: un análisis de contenido
}

Recebido: 15/11/2021 | Revisado: 24/11/2021 | Aceito: 25/11/2021 | Publicado: 07/12/2021

\author{
Raphael Braz de Carvalho \\ ORCID: https://orcid.org/0000-0002-2235-1181 \\ Universidade Federal Fluminense; Brasil \\ E-mail: phbraz@yahoo.com.br \\ Magda de Souza Chagas \\ ORCID: https://orcid.org/0000-0002-3616-6745 \\ Universidade Federal Fluminense; Brasil \\ E-mail: magdachagas@id.uff.br \\ Ana Lúcia Abrahão da Silva \\ ORCID: https://orcid.org/0000-0002-0820-4329 \\ Universidade Federal Fluminense; Brasil \\ E-mail: abrahaoana@gmail.com
}

\begin{abstract}
Resumo
Objetivo: Analisar e refletir sobre a criação de aplicativo móvel para Enfermagem Oncológica a partir do olhar profissional. Método: Esta pesquisa possui abordagem qualitativa e quantitativa e foi desenvolvida a partir da metodologia de Análise de Conteúdo proposta por Bardin, com 17 enfermeiros especialistas em Enfermagem Oncológica, atuantes em uma instituição de saúde orientada aos cuidados ao paciente com câncer. Devido à pandemia de COVID-19, foi realizada inicialmente em caráter virtual, contudo, após a vacinação, em meio presencial. Os dados foram coletados por meio de transcrições dos encontros virtuais e presenciais e analisados pela perspectiva de Bardin. Resultados: $\mathrm{Na}$ análise, foi possível observar que os profissionais identificam a tecnologia digital como meio de formação no espaço de trabalho e que o desenvolvimento de uma ferramenta voltada à Enfermagem Oncológica agregaria conhecimento confiável e útil. Considerações finais: O objeto de estudo encontrou apoio nas considerações de todos os grupos apresentados. Foi observado que, independente da estrutura funcional escolhida, é de grande importância para a categoria da Enfermagem poder contar com acesso rápido à educação permanente em saúde voltada para o câncer.
\end{abstract}

Palavras-chave: Análise de conteúdo; Enfermagem; Tecnologia móvel.

\begin{abstract}
Objective: Analyze and reflect on the creation of a mobile application for Oncology Nursing from a professional perspective. Methodology: This research has a qualitative and quantitative approach based on the content analysis methodology by Bardin, it was carried out with 17 specialist nurses in Oncology Nursing working at a cancer patient care institution. Due to the COVID-19 pandemic, was carried out at first in character virtual and after in-person vaccination. Data were collected from transcripts of virtual and face-to-face meetings and analyzed from Bardin's perspective. Results: In the analysis, it was possible to observe that professionals identify digital technology as a means of training in the workplace and the development of a tool aimed at Oncology Nursing would add reliable and useful knowledge. Final considerations: The object of study found support in the considerations of all the groups presented. It was observed that, regardless of the chosen functional structure, it is of great importance for the Nursing category to have quick access to permanent health education focused on cancer.
\end{abstract}

Keywords: Content analysis; Nursing; Mobile technology.

\section{Resumen}

Objetivo: Analizar y reflexionar sobre la creación de una aplicación móvil para Enfermería Oncológica desde una perspectiva profesional. Método: Esta investigación tiene un enfoque cualitativo y cuantitativo y fue desarrollada a partir de la metodología de Análisis de Contenido propuesta por Bardin, con 17 enfermeros especialistas en Enfermería Oncológica, asistentes de una institución de salud dedicada a la atención de pacientes oncológicos. Debido a la pandemia de COVID-19, esta se realizó inicialmente de forma virtual, sin embargo, además de la vacunación, en persona. Los datos recopilados a través de transcripciones son dos encuentros virtuosos presenciados y analizados desde la perspectiva de Bardin. Resultados: En el análisis se pudo observar que los profesionales identifican la tecnología digital como un medio de formación y no como un espacio de trabajo, y que el desarrollo de una herramienta dirigida a la Enfermería Oncológica sumaría conocimientos fiables y útiles. Consideraciones finales: El objeto de estudio encontró apoyo en las consideraciones de todos los grupos presentados. Se observó que, independientemente de la estructura 
funcional elegida, es de gran importancia que la categoría de Enfermería tenga acceso rápido a la educación permanente en salud enfocada en el cáncer.

Palavras clave: Análisis de contenido; Enfermería; Tecnología móvil.

\section{Introdução}

Em um olhar iniciante de pesquisador, realizar estudo de abordagem qualitativa, a fim de que haja uma interação entre as pessoas e a construção de soluções que modifiquem sua realidade, é uma atitude que desloca os seres humanos em suas relações e extrai narrativas tanto pessoais quanto focadas no objeto de estudo. Assim, o objetivo deste artigo é discutir, em coletivo, sobre a Criação de Aplicativo Móvel para Enfermagem Oncológica, um tema atual, porém, pouco compreendido em seus detalhes pela categoria da enfermagem.

Durante a pesquisa, observamos que o corpo de cada participante se movimentava explícita e subjetivamente empolgado por ajudar na construção dessa ferramenta tecnológica e todas estas observações precisam ser analisadas. Para isso, escolhemos a Análise de Conteúdo (AC) proposta por Bardin (2004, 2010 e 2011) como método de análise dos encontros, a partir das transcrições do reunido nas conversas e pela percepção do pesquisador sobre cada participante.

A sociedade permanece em transformação e a Cultura Digital se apresenta como práticas sociais capazes de reconfigurar aspectos e funções da vida. Nesse contexto, a escola e seus professores configuram atores que também recebem essa cultura posta pelas tecnologias digitais, utilizada para os mais diversos fins, alterando fortemente as formas de comunicação, informação e interação (Ferreira, 2020; Sousa \&Turrini., 2019).

O cenário da pesquisa compreende uma instituição de saúde especializada em atendimento a pessoas com câncer. Devido à pandemia de COVID-19, os instrumentos virtuais utilizados para a elaboração do estudo foram o Whatsapp e a Plataforma Zoom, posteriormente, após a vacinação, ocorreram encontros presenciais em ambiente institucional, respeitando as normas de biossegurança. Foram convidados, por mensagens de texto, 17 participantes enfermeiros atuantes na instituição e realizados 05 encontros, sendo 03 virtuais e 02 presenciais. Todos os convidados optaram por participar da pesquisa.

Os instrumentos utilizados na pesquisa foram: 1) Convite via Whatsapp; 2) Videochamada para aproximar o pesquisador do participante, de modo a quebrar a formalidade; 3) Termo de Consentimento Livre e Esclarecido (TCLE), encaminhado para ciência da pesquisa; 4) Formulário do Google Forms, enviado para conhecer os participantes e identificar o quanto eles se familiarizavam com ferramentas tecnológicas; e 5) Plataforma Mentimeter, utilizada com o objetivo de aplicar um brainstorm (chuva de ideias) e identificar sugestões de ferramentas tecnológicas aleatórias e temas que direcionariam novas abordagens.

A coleta de dados foi realizada por imagem e voz nos encontros virtuais e por gravação de voz nos presenciais. Ao iniciar a análise, observamos que, a cada encontro, o movimento e a conversa delineavam-se por corpo, movimento e voz. Após o término dos encontros, foi realizada a transcrição das falas para o tratamento do material.

Os encontros findaram com os participantes apoiando o objetivo da pesquisa e com evidências de que mais vieses não surgiriam. Deste modo, solidificou-se, com maior clareza, a criação de um Aplicativo Móvel voltado para a Enfermagem Oncológica como resultado pretendido a partir das reuniões.

O Termo de Consentimento Livre e Esclarecido (TCLE) foi previamente aprovado sob o CAAE: 33564820.1 .0000 .5626 e, por anuência institucional, esta pesquisa teve o objetivo de adquirir cooperação e conhecimento sobre a ferramenta tecnológica Aplicativo Móvel para Enfermagem Oncológica e obter as considerações sobre o que mais se aproximava da realidade da categoria, respostas imprescindíveis para dar continuidade à construção do aplicativo (CNS, 2018). 


\section{Metodologia}

A exploração do material seguiu o rigor do método definido por Bardin em um movimento de imersão do pesquisador nestes dados (Sousa \& Santos, 2020; Bardin, 2004, 2010 e 2011). A pesquisa qualitativa objetiva responder as respostas de maneira sistemática e racional e possibilitar construir métodos capazes de mudar a realidade onde se inseriu o problema (Gil, 2007). Definiu-se esta técnica por ser capaz de analisar os pontos centrais das transcrições, na busca do sentido ou sentidos dos elementos recolhidos nos encontros, e pela Análise de Conteúdo ser um instrumento de avaliação de dados qualitativos e quantitativos, os quais podem se apresentar por entrevistas, vídeos, conversas e textos, entre outras maneiras de reunir informações. A partir de um rigor científico e do conjunto de técnicas deste método, o pesquisador obtém resultados para a elucidação do objeto e a compreensão dos participantes conforme a dinâmica, o discurso e aquilo que está oculto no discurso (Mendes \& Miskulin, 2017).

Historicamente, a Análise de Conteúdo surgiu com a tentativa de interpretação bíblica em seus símbolos, sinais e mensagens. Posteriormente, no século XVII, mais precisamente em 1640 na Suécia, buscou-se a veracidade e o estilo de hinos luteranos. No período de 1888-1892, B. Bourbon expressou a linguagem de textos bíblicos e, em 1948, Berelson, Lazarsfeld e Lasswell foram considerados os marcos criadores da análise de conteúdo, com o primeiro se destacando em apresentar a AC visando a uma comunicação de maneira objetiva, sistemática e quantitativa (Campos, 2004).

No entanto, a AC ficou conhecida por Bardin (1977) descrevendo-a como um conjunto de técnicas de análise das comunicações (vídeos, encontros, entrevistas, etc), utilizando procedimentos sistemáticos e objetivos de descrição do conteúdo das mensagens. Segundo a autora, é o conjunto dos documentos que serão submetidos à análise com a intenção e inferência de conhecimentos relativos às condições de produção (Mendes \& Miskulin, 2017).

Minayo (2001) define a pesquisa qualitativa como interpretação do comportamento humano e considera suas percepções, crenças e valores adquiridos por toda a vida. Este modo de pensar sobre pesquisa qualitativa possibilita a construção de novas abordagens respeitando a diversidade de cada ser que participa e se faz parte do problema a ser respondido, assim, esta modalidade de pesquisa não deve se diminuir como operativo, pois são consideradas as opiniões, sentimentos, atitudes e interpretação dos fenômenos sociais. Do mesmo modo, Pope e Mays (2005) entendem estes significados como a relação das pessoas com o mundo em que estão inseridas, observando como ato interpretativo este modo de pesquisa. Assim, Minayo (2014) suscita a construção de uma pesquisa onde a operacionalização seja íntima do sentido social, histórico e das várias possibilidades de produção que esta união pode gerar.

Estes autores também resgatam a relação entre a pesquisa qualitativa e quantitativa como métodos que são usados em conjunto para responder à questão de pesquisa e, desta forma, um método complementa o outro (Pope \& Mays, 2005).

O caminho percorrido nesta pesquisa está apresentado na Figura 1, a seguir, onde se observa que o estudo se desenvolveu a partir da avaliação do material, reflexão, separação dos dados objetivos e implícitos de acordo com o objeto criação de aplicativo para celular e tratamento dos resultados, análise e interpretação. 
Figura 1. Desenvolvimento da Pesquisa.

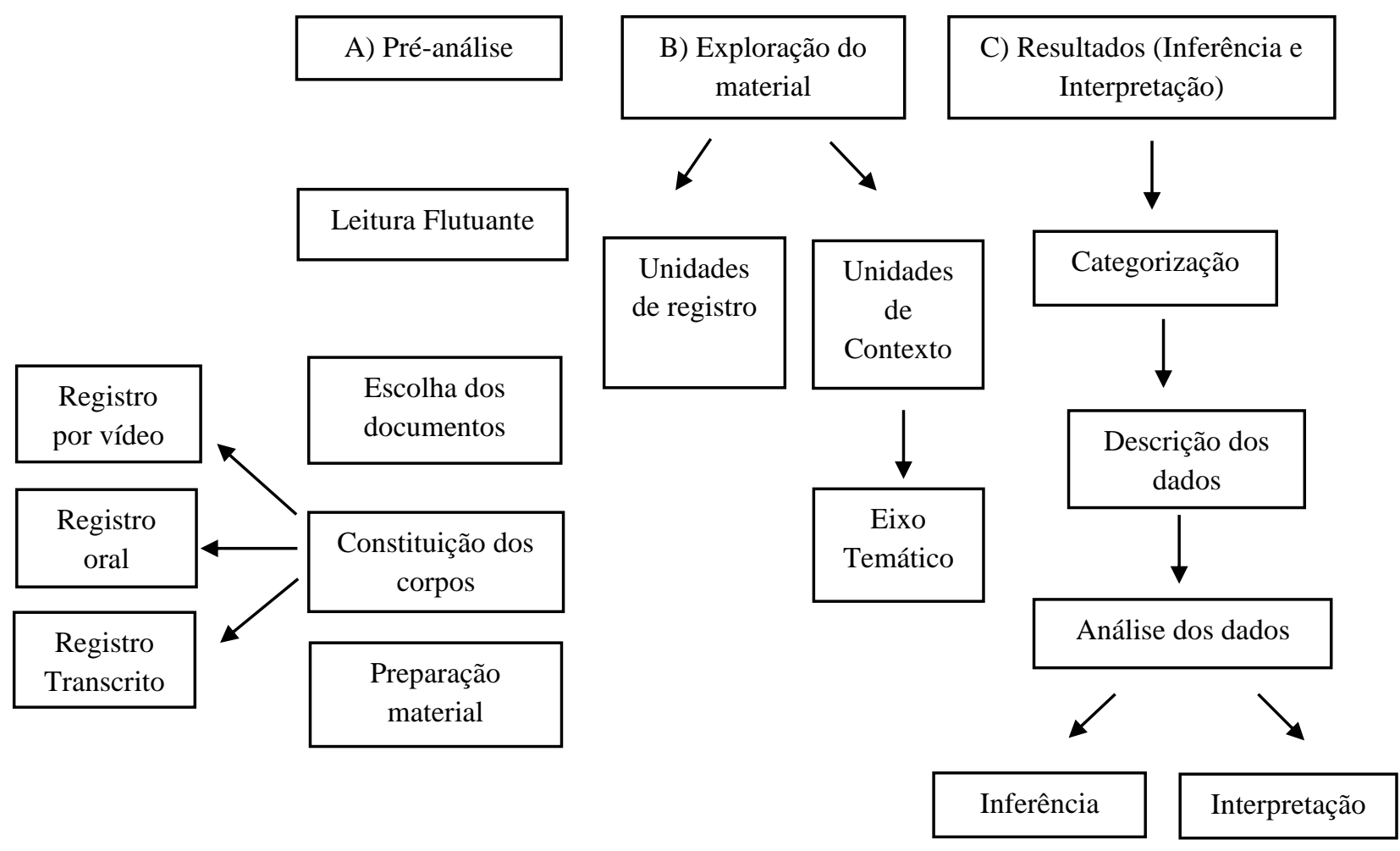

Fonte: Adaptado de Bardin (1977).

Para manter o rigor da pesquisa, realizamos a análise conforme a técnica estruturada por Bardin (2011) em três fases: Pré-análise, Exploração do material, categorização ou codificação, Tratamento dos resultados, inferências e interpretação.

\subsection{Pré-análise}

Na pré-análise, foi realizada a leitura flutuante do material a fim de compreender e estruturar aspectos importantes, aplicando o "olhar de fora, sem julgamentos". O objetivo foi captar a ideia central óbvia (criar um aplicativo móvel) e não óbvia (outros olhares para ferramentas tecnológicas apresentadas), além de hipóteses (qual outra ferramenta tecnológica poderíamos criar para educação em enfermagem oncológica?) e indicadores na leitura e releitura, importantes para seguir com as sub-etapas da primeira fase (Bardin, 1977 e 2010), indicadas a seguir.

Regra de exaustividade, onde a autora preconiza que todos os elementos do documento foram buscados e alcançados, sem deixar nada em oculto (Bardin, 1977 e 2010). Este foi o momento em que voltamos ao $5^{\circ}$ encontro para solidificar o objeto de estudo (criação de aplicativo móvel) e sua construção conforme afirmado pelos participantes, observando também o aperfeiçoamento do pesquisador como agente organizador da pesquisa.

Regra da representatividade, quando a amostra é rigorosa se for parte representativa do universo que será analisado (Bardin, 1977 e 2011). Nesta sub-etapa, poderíamos escolher parte do material, mas por ser uma abordagem qualitativa com objeto comum explícito (aplicativo de celular), abordar o todo seria de melhor elucidação dos objetivos da pesquisa.

Regra da homogeneidade, onde são escolhidos documentos que não suscitam outro assunto a não ser o do material a ser analisado (Bardin, 1977 e 2011). Aqui, por se tratar do tema novamente explícito (aplicativo de celular) aos participantes, não houve problemas e não foi necessário estratificar por temas diversos. 
Regra de pertinência, onde os documentos retirados devem responder todas as informações que a análise pede, conforme o objeto de estudo (Bardin, 1977 e 2011). Neste tópico, bem como na regra de homogeneidade, entendemos que os documentos escolhidos foram adequados para a análise, pois são semelhantes e dialogam por temas em ferramentas tecnológicas para celular.

\subsection{Exploração do material}

O pesquisador seleciona o material por palavras e frases aquilo que chama sua atenção, sendo que a escolha é precedida pelo abordado e está aflorando no material. Neste momento, é difícil constatar interdependência das escolhas do pesquisador apesar dele buscar o melhor e mais adequado ao seu material. Fatores pessoais não devem sobrepor o rigor da pesquisa e inferir na veracidade dos resultados (Campos, 2004).

\subsection{Tratamento dos resultados, inferências e interpretação}

Nesta fase, a transcrição foi tratada conforme o objeto de estudo, tecnologia móvel, e o olhar do participante como pessoa que pode opinar e mudar sua realidade. Os eixos serão apresentados em quadros para melhor exemplificação e simplificação, respeitando o rigor de Bardin (1977), e a análise se mostra a partir da classificação do conjunto, considerando cada especificidade para reagrupação dos mesmos em critérios acordados.

A dança do ir e vir no texto possibilitou a consideração de aspectos importantes, antes não observados, e a desconsideração daqueles que já estavam inerentes à pergunta a ser respondida.

Abordamos os princípios de rigor metodológico considerando a análise de conteúdo em: Exclusão mútua, quando um elemento coexiste sozinho em uma seção dos quadros; Homogeneidade, onde este elemento traduz toda a continuidade da sua linha de pensamento e descrição; Pertinência, quando o material suscita o tema proposto do objeto de estudo; Objetividade e fidelidade, onde os elementos, ainda que diferentes, devem ser tratados semelhantemente em consideração e julgamento, mesmo se características verbais desacordem com as não verbais, como exemplo, apresentando-se em mesma linha no quadro expositivo, por isso, o estudo deve ser explicado pormenorizadamente; e Produtividade, quando o elemento fornece veracidade das informações apresentadas e dele pode-se expandir conhecimento (Bardin, 1977; Mendes \& Miskulin, 2017).

\section{Resultados}

Ao formular hipóteses acerca do objetivo, foi apresentada a possibilidade de criação de um aplicativo para celular, no entanto, dentro de um aplicativo, existem diversos recursos e funcionalidades (Cruz et al., 2020). Um Aplicativo ou Application (termo em inglês), abreviado por "App", fica disponibilizado em distribuidoras digitais Google/Apple Store e pode ser executado nos sistemas operacionais móveis Android, iOS e Windows Phone (Cruz et al., 2020). Como vivemos em constante transformação enquanto sociedade, as tecnologias digitais constituem instrumentos disponíveis para aliar as práticas de cuidado na formação profissional por meios virtuais e atualmente apresentam-se fortemente como novas formas de interação (Ferreira, 2020). A Organização Mundial da Saúde (OMS) e o Conselho federal de Enfermagem (COFEN) citam os telefones celulares como ferramentas usadas para comunicação, educação, consumo, entretenimento e outras diversas funcionalidades por aplicativos e outras mídias que convergem deste aparelho (Cruz et al., 2020; Cofen, 2017).

Nesse contexto, é válido destacar que o uso da tecnologia móvel é substancialmente aplicado nas práticas de enfermagem atuais, pois ajuda a melhorar a segurança do cuidado ao paciente com maior interação e rapidez, por meio de subsídios científicos disponíveis nesta nova realidade (Dionizio, 2017; Silveira \& Cogo, 2017). 
O Quadro 1 mostra as ferramentas e formas operacionais que os participantes sugeriram para criação. Este quadro indica que os participantes, quando sugerem a palavra "aplicativo", referem em sentido amplo, ou seja, tudo pode surgir, existem várias possibilidades e recursos a partir de um aplicativo.

Quadro 1. Ferramentas e formas operacionais sugeridas para criação.

\begin{tabular}{|l|c|}
\hline \multicolumn{1}{|c|}{ Funcionalidade } & Quantidade sugerida* \\
\hline Aplicativo & 72 vezes \\
\hline Podcast & 35 vezes \\
\hline Gameficação & 02 vezes \\
\hline Vídeos & 06 vezes \\
\hline Blog/Vlog & 02 vezes \\
\hline
\end{tabular}

*Os sinônimos foram incluídos na palavra de origem.

Fonte: Elaboração própria (2021).

O Quadro 2 detalha como se desenvolveu a conversa com os participantes, em modo virtual ou presencial, os quais foram nominados ficticiamente por influentes da enfermagem e por concepção pessoal do pesquisador, além de numerados de 01 a 17; por fim, foi descrita a modalidade do encontro, local e instrumento utilizado.

Quadro 2. Encontros, participantes e suas descrições.

\begin{tabular}{|l|l|l|l|}
\hline \multicolumn{1}{|c|}{ Conversa } & \multicolumn{1}{|c|}{ Reuniões/Datas } & \multicolumn{1}{c|}{ Participantes } & \multicolumn{1}{c|}{ Descrição } \\
\hline $\begin{array}{l}\text { Encontro Virtual -Registro de } \\
\text { imagem e voz }\end{array}$ & $\begin{array}{l}1^{\circ} \text { Encontro } \\
21 / 10 / 2020\end{array}$ & $\begin{array}{l}\text { Nery (01), Orem (02), } \\
\text { Florence (03), } \\
\text { Imogene (04), Ivone } \\
(05)\end{array}$ & Encontro virtual pela Plataforma Zoom \\
\hline $\begin{array}{l}\text { Encontro Virtual - Registro de } \\
\text { imagem e voz }\end{array}$ & $\begin{array}{l}2^{\circ} \text { Encontro } \\
13 / 11 / 2020\end{array}$ & $\begin{array}{l}\text { Maria Rosa (06), } \\
\text { Horta (07) }\end{array}$ & Encontro virtual pela Plataforma Zoom \\
\hline $\begin{array}{l}\text { Encontro Presencial - Registro } \\
\text { de som }\end{array}$ & $\begin{array}{l}3^{\circ} \text { Encontro } \\
12 / 12 / 2020\end{array}$ & $\begin{array}{l}\text { Claudio (08), Callista } \\
(09)\end{array}$ & $\begin{array}{l}\text { Realizado na Supervisão de Enfermagem, } \\
\text { respeitando o distanciamento e as medidas de } \\
\text { biossegurança }\end{array}$ \\
\hline $\begin{array}{l}\text { Encontro Presencial - Registro } \\
\text { de som }\end{array}$ & $\begin{array}{l}4^{\circ} \text { Encontro } \\
11 / 01 / 2020\end{array}$ & $\begin{array}{l}\text { Martha (10), Elza } \\
(11), \text { Olga (12) }\end{array}$ & $\begin{array}{l}\text { Realizado no 8 }{ }^{\circ} \text { andar, respeitando o } \\
\text { distanciamento e as medidas de biossegurança }\end{array}$ \\
\hline $\begin{array}{l}\text { Encontro Presencial - Registro } \\
\text { de som }\end{array}$ & $\begin{array}{l}5^{\circ} \text { Encontro } \\
10 / 02 / 2021\end{array}$ & $\begin{array}{l}\text { Cicely (13), Rachel } \\
(14), \text { Marie (15), } \\
\text { Conceição (16), } \\
\text { Ivanise (17) }\end{array}$ & $\begin{array}{l}\text { Realizado no salão de quimioterapia, } \\
\text { respeitando o distanciamento e as medidas de } \\
\text { biossegurança }\end{array}$ \\
\hline
\end{tabular}

Fonte: Elaboração própria (2021).

Sobre o objeto de pesquisa, o Quadro 3 expõe como ocorreu a explicação aos participantes, a partir de eixos temáticos seguidos das reflexões sobre o desabrochar do que gostaria de ser mostrado. 
Quadro 3. Eixos temáticos e suas propostas de acordo com a estratégia da pesquisa.

\begin{tabular}{|l|l|}
\hline \multicolumn{1}{|c|}{ Eixo Temático } & \multicolumn{1}{c|}{ Temas Iniciais } \\
\hline \multirow{2}{*}{ Produto na forma de App } & $\begin{array}{l}\text { Proposta a criação de um aplicativo para celular voltado para educação permanente em } \\
\text { enfermagem em oncologia. }\end{array}$ \\
\hline \multirow{4}{*}{$\begin{array}{l}\text { TICs (Tecnologias da } \\
\text { Informação e Comunicação) }\end{array}$} & Reflexões sobre o uso das TICs. \\
\cline { 2 - 3 } & Reflexões sobre o uso das TICs como meio educacional. \\
\cline { 2 - 3 } & Uso das TICs ou não e visão sobre. \\
\cline { 2 - 3 } & $\begin{array}{l}\text { Sentimentos sobre as TICs } \\
\text { Exemplificadas as características e categorizações dos modos/formato que poderiam ser } \\
\text { trabalhados e qual deles seria mais aceito para a categoria, exemplo: software com textos e } \\
\text { imagens, vídeos, podcasts (áudios), gameficação. }\end{array}$ \\
\hline \multirow{3}{*}{ Conteúdos prioritários } & $\begin{array}{l}\text { Solicitado ao ver, de cada participante, qual ordem de conteúdo deveria aparecer do primeiro em } \\
\text { diante. }\end{array}$ \\
\hline
\end{tabular}

Fonte: Elaboração própria (2021).

Os trechos destacados na sequência exemplificam algumas falas dos participantes quanto à utilização de um aplicativo móvel em suas práticas profissionais, bem como sugestões do que poderia ter nesta ferramenta.

Eu acho que o aplicativo pode ter podcast (...). Podcast é bem legal, porque sempre um tema atual (...) Neri (01)

Um aplicativo ele pode fazer muita coisa, você pode usar tanto o auditivo quanto o visual, quanto palestras (vídeos). Orem (02)

A impressão que dá é que tudo é possível dentro de um aplicativo. Florence (03)

Então, ele (o aplicativo) pode ter um link que gere o texto em pdf, (...) e ele pode ter um link para vídeos e podcast ou áudios para ouvir no carro, voltando para casa. Imogene (04)

Eu acho que, assim, no contexto geral, se a gente conseguir colocar para funcionar um aplicativo, seria o ideal. Ivone (05)

(...) e aí dentro do aplicativo funcionando, você consegue avaliar qual é a demanda e ter o seu produto ideal. Maria Rosa (06)

Eu acho que um aplicativo que tivesse uma funcionalidade do tipo assim "qual a sua dúvida hoje?", "O que você gostaria de relembrar hoje?" (...) fico imaginando assim, uma coisa tipo (...) bem ampla. Horta (07)

(...) é só de você compilar isso num aplicativo só, ia ajudar muito a nossa vida. Claudio (08)

Porque assim, eu acho que num contexto de formação, se você for pensar em formação ou educação permanente (...). Vamos dizer, a gente vai trabalhar dentro do conteúdo de enfermagem oncológica. Vamos entrar aqui para a gente fazer a educação permanente na enfermagem oncológica. Claudio (08)

(...) acho que a tecnologia veio para ficar realmente. Em alguns momentos híbrida, (...) ela veio para auxiliar em todos os sentidos, não só o paciente, mas acho super importante ter na nossa vida prática também, para nos auxiliar 
nessa parte da educação. E como toda educação permanente ela vem da gente, porque as necessidades têm que serem vistas. Cicely (13)

Então, para o enfermeiro se comunicar melhor, assistir melhor o seu paciente, orientar melhor a sua equipe precisa disso. Martha (10)

A gente avalia o conteúdo (...) em determinado assunto. Como quimioterapia, cirurgia, radioterapia e avalia e "olha tá muito ruim em radioterapia, vamos trabalhar? vamos!" Pessoal sabe pouco sobre extravasamento ou manutenção de cateter de longa permanência (...). A gente vai pontuar os principais pontos e isso é educação permanente. Callista (09)

Eu acho que, assim, no contexto geral, se a gente conseguir colocar para funcionar um aplicativo, seria o ideal. Todo temos smartphone, todos, 100\%! Olga (12)

(...) podcast é aquela coisa assim, por exemplo, eu ouço podcast, eu sou flamenguista roxo, eu ouço podcast do flamengo. Callista (09)

Mas o podcast é muito inerte, você não troca. Marie (15)

Uma das possibilidades seria o podcast, mas assim, no caso do smartphone, tivesse um aplicativo para a pessoa poder trocar, chegar, jogar uma informação ali e tal, seria mais produtivo. Elza (11)

A gente pode decidir que ele tem artigos, ou que tenha textos escritos? Exemplo: câncer de pulmão. Aí escreve lá o que é o câncer de pulmão, diagnóstico, tratamento, novidades (...) essas coisas (entendeu?), ou seja, a gente pode fazer algo escrito (...) Ivanise (17)

Um exemplo de assunto: quimioterapia. Aí aparece lá e ele vai e olha, borda e lê. Conceição (16)

E até avaliar coisas assim, "o que você avalia da importância da assistência em relação à náusea pós quimioterapia ou pré quimioterapia" e ele avalia. Rachel (14)

É "o que você faz no extravasamento? Como você age?" (...) Quimioterapia vai te dar várias alternativas Pré-QT, complicações, extravasamentos e tal, pós QT (...) Conceição (16)

Adjuvante, neoadjuvante, vesicante, irritante. Rachel (14)

Para organizar as considerações e percepções observadas nos encontros, foram propostos cinco eixos, dispostos nas colunas do Quadro 4, sendo estes: Categorias - aborda os tópicos que serão analisados; Subcategorias - o caminho apresentado, percepções verbais e não verbais; Unidades de registro - a compreensão quanto ao objeto de pesquisa ou não; Unidades de contexto - as observações recolhidas; e Opinião do pesquisador - sua consideração de acordo com o visualizado, sem realizar julgamentos. 
Quadro 4. Principais concepções a serem analisadas.

\begin{tabular}{|c|c|c|c|c|}
\hline Categorias & Subcategorias & $\begin{array}{c}\text { Indicadores/ } \\
\text { Unidades de registro }\end{array}$ & Unidades de Contexto & Opinião do pesquisador \\
\hline $\begin{array}{l}\text { 1. Percepção } \\
\text { sobre aplicativo }\end{array}$ & $\begin{array}{l}\text { Proposição relevante } \\
\text { do participante }\end{array}$ & $\begin{array}{l}\text { Objeto específico: } \\
\text { aplicativo/celular }\end{array}$ & $\begin{array}{l}\text { Expressada na frase, } \\
\text { expressão gestual, } \\
\text { inespecífica/solta }\end{array}$ & $\begin{array}{l}\text { Reflexão geral sobre } \\
\text { educação por aplicativo } \\
\text { móvel }\end{array}$ \\
\hline $\begin{array}{l}\text { 2. Experiência } \\
\text { com as TICs }\end{array}$ & $\begin{array}{l}\text { Inclusão/ Exclusão } \\
\text { Digital }\end{array}$ & $\begin{array}{l}\text { Demonstra exemplos e } \\
\text { opina sobre a operação }\end{array}$ & $\begin{array}{l}\text { Expressada na conversa } \\
\text { e entendimento sobre o } \\
\text { tema }\end{array}$ & $\begin{array}{l}\text { Se o participante demonstra } \\
\text { interesse ou aplica a } \\
\text { ferramenta }\end{array}$ \\
\hline $\begin{array}{l}\text { 3. Resposta ao } \\
\text { pré-teste via } \\
\text { Mentimeter e } \\
\text { Google Forms }\end{array}$ & $\begin{array}{l}\text { Realizou ou não o } \\
\text { teste }\end{array}$ & $\begin{array}{l}\text { Desenvolve interesse e } \\
\text { envolvimento sobre a } \\
\text { pesquisa. }\end{array}$ & $\begin{array}{l}\text { Compreensão do } \\
\text { assunto }\end{array}$ & $\begin{array}{l}\text { Teve acessibilidade e fácil } \\
\text { manuseio }\end{array}$ \\
\hline $\begin{array}{l}\text { 4. Sentimentos } \\
\text { sobre as TICs }\end{array}$ & Reflexão & $\begin{array}{l}\text { Expressou bloqueio ou } \\
\text { facilidade }\end{array}$ & $\begin{array}{l}\text { Expressou } \\
\text { aplicabilidade ou } \\
\text { negação ao aplicativo }\end{array}$ & $\begin{array}{l}\text { Bloqueio ou facilidade em } \\
\text { adaptação as tecnologias } \\
\text { digitais }\end{array}$ \\
\hline $\begin{array}{l}\text { 5. Relacionados } \\
\text { ao desempenho } \\
\text { profissional }\end{array}$ & $\begin{array}{l}\text { Utilização de App } \\
\text { no cotidiano }\end{array}$ & $\begin{array}{l}\text { Prefere outros modos } \\
\text { para aprendizado }\end{array}$ & $\begin{array}{l}\text { Demonstrou poucas } \\
\text { possibilidades a partir } \\
\text { desta ferramenta }\end{array}$ & $\begin{array}{l}\text { Profissional mal preparado, } \\
\text { desinteressado/ } \\
\text { desmotivado }\end{array}$ \\
\hline $\begin{array}{l}\text { 6. Relacionados a } \\
\text { conteúdos, } \\
\text { atividades e } \\
\text { avaliação }\end{array}$ & $\begin{array}{l}\text { Utilização de App } \\
\text { no cotidiano }\end{array}$ & $\begin{array}{l}\text { Observa melhores } \\
\text { alternativas de } \\
\text { construção do } \\
\text { aprendizado } \\
\end{array}$ & $\begin{array}{l}\text { Participa e sugere } \\
\text { assertivamente sobre } \\
\text { sua prática assistencial }\end{array}$ & $\begin{array}{l}\text { Carência de aulas/atividades } \\
\text { práticas, conteúdo } \\
\text { superficial, incompleto ou } \\
\text { mal preparado }\end{array}$ \\
\hline $\begin{array}{l}\text { 7. Relacionados à } \\
\text { organização e } \\
\text { chefias }\end{array}$ & $\begin{array}{l}\text { Utilização de App } \\
\text { por instituições }\end{array}$ & $\begin{array}{l}\text { Observa ausência de } \\
\text { impacto nas chefias } \\
\text { para factibilizarem a } \\
\text { implantação }\end{array}$ & $\begin{array}{l}\text { Demonstra uso do } \\
\text { tempo para outras } \\
\text { atividades no local de } \\
\text { trabalho }\end{array}$ & $\begin{array}{l}\text { Falta de diálogo, carga } \\
\text { horária de assistência } \\
\text { elevada, imposição }\end{array}$ \\
\hline $\begin{array}{l}\text { 8. Relacionados } \\
\text { aos recursos } \\
\text { físicos }\end{array}$ & $\begin{array}{l}\text { Não há apoio/ } \\
\text { orientação }\end{array}$ & $\begin{array}{l}\text { Observa pouca } \\
\text { interação via TIC }\end{array}$ & $\begin{array}{l}\text { Demonstra dificuldades } \\
\text { com a TIC }\end{array}$ & $\begin{array}{l}\text { Carência de aparelho móvel, } \\
\text { rede de apoio ou estratégia } \\
\text { direcionada de consulta de } \\
\text { material }\end{array}$ \\
\hline
\end{tabular}

Fonte: Elaboração própria (2021).

Acerca da percepção sobre os aplicativos, a maioria dos participantes conhece bem a ferramenta, utiliza e acredita que possa ser uma modalidade educacional factível e atingível na população da enfermagem oncológica. Foram realizadas proposições relevantes e descritas, várias vezes, as palavras "aplicativo" e "celular". Sendo assim, entende-se que a criação de um aplicativo móvel será uma ferramenta otimizadora de informação e conhecimento para quem se dispor a usá-la.

No que se refere à experiência com as TICs, os participantes não descrevem exatamente as múltiplas modalidades existentes, porém, conhecem e assemelham que o adequado uso de cada uma delas, em junção ou separadas, será fator um otimizador educacional (Gomes et al., 2019; Guimarães et al., 2018).

Os participantes, em sua maioria, responderam os testes de sugestões e opiniões e sugeriram adequação das perguntas. Alguns não responderam por problemas de conexão ou software de aparelho móvel próprio. Além disso, abordaram as perspectivas que atravessam toda construção, pesquisa e estudos que envolvem pessoas e a participação delas na mudança de sua realidade.

Observamos uma diversidade de sensações e sentimentos ao se tratar de TICs, desde euforia, empolgação, entusiasmo, proatividade, colaboração e coleguismo em sua maioria a receio de pré-julgamentos por outros integrantes do grupo, dificuldade em exposição de ideias em grupo e inexperiência do pesquisador nos primeiros encontros. 
Identificamos como cada participante opera sua relação com o ambiente tecnológico e o aplica em sua realidade, se procura este ambiente para desenvolvimento educacional permanente e a forma deste manejo quanto ao sentido/momento que ele procura esta ferramenta. Há um reconhecimento da importância e praticidade de uma ferramenta tipo aplicativo, contudo, observamos que a utilização de outras formas de busca pelo conhecimento também se faz presente.

Por fim, percebeu-se que a disposição das instituições em saúde, conselhos e órgãos que regem a profissão necessitam de incentivo, apoio e construção deste viés novo de educar diante de um cenário de ausências de recursos físicos direcionados à clientela a ser atingida, incluindo o mais básico, que seria o celular, passando pela conexão e apresentação dos dados.

\section{Considerações Finais}

Ao seguir o método Análise de Conteúdo e as expectativas da pesquisa, entendemos que o objeto de estudo "Criação de um Aplicativo" encontra apoio nas considerações de todos os grupos apresentados. Foi observado que, independente da estrutura funcional escolhida, é de grande importância para a categoria de Enfermagem poder contar com acesso rápido à educação permanente em saúde voltada para o câncer.

A análise ocorreu por meio da percepção dos participantes envolvidos na pesquisa, não sendo observadas alegações sobre impedimentos ao objeto de estudo a ser construído. Em geral, vale destacar o apoio mútuo dos participantes neste desafio.

Neste estudo, a Análise de Conteúdo contribuiu para a observação sistemática das transcrições como assertivas lógicas e generalizadas. A partir desta, podemos inferir as ligações não verbais favoráveis apresentadas também pelos participantes (esta fase admite afirmações primeiras ligadas a afirmações esperadas).

Assim, como toda técnica precisa ser estudada, praticada e aprimorada, este estudo se abriu em crítica abstrata por apresentar exponencial tamanho e atingibilidade caso realmente seja implantado para a sociedade. Mantemos o propósito de conseguir construir uma ferramenta confiável e útil.

Por fim, esperamos que esta modalidade de estudo reverbere na comunidade acadêmica favorecendo construções que registrem os olhares, sentimentos, percepções e acolha a trajetória profissional e pessoal dos participantes, de modo que juntos, possam construir novas formas de produção de conhecimento, em tecnologia e diversas áreas como educação, saúde, governos e sociedade.

\section{Referências}

Bardin, L. (1977). Análise de conteúdo. Edições 70.

Bardin, L. (2004). Análise de conteúdo. Edições 70.

Bardin, L. (2010). Análise de conteúdo. Edições 70.

Bardin, L. (2011). Análise de conteúdo. Edições 70.

Brasil. Conselho Nacional de Saúde. (2018). Resolução $n^{\circ} 580$, de 22 de março de 2018. Regulamenta o disposto no item XIII da Resolução CNS nº 466, de 12 de dezembro de 2012, que estabelece que as especificidades éticas das pesquisas de interesse estratégico para o Sistema Único de Saúde (SUS) serão contempladas em Resolução específica, e dá outras providências. Brasília: CNS.

Campos, C. J. G. (2004). Método de análise de conteúdo: ferramenta para a análise de dados qualitativos no campo da saúde. Revista Brasileira de Enfermagem, 57(5), 611-614.

Conselho Federal de Enfermagem. (2017). Cofen apoia pesquisa sobre uso de tecnologias na saúde. http://www.cofen.gov.br/cofen-apoia-pesquisa-sobre-usode-tecnologias-na-saude_48443.html

Cruz, S. C. S., Nunes, K. A. C., Muri, L. A. C., Lima, E. F. A., Sant'anna, H. C., Fioresi, M., Furieri, L. B., \& Primo, C. C. (2020). Capítulo 5: Métodos e plataformas gratuitas para o desenvolvimento de aplicativos. In: Teixeira, E., organizadora. Desenvolvivento de técnologias cuidativo-educacionais. Porto Alegre: Moriá. 
Research, Society and Development, v. 10, n. 16, e81101623347, 2021

(CC BY 4.0) | ISSN 2525-3409 | DOI: http://dx.doi.org/10.33448/rsd-v10i16.23347

Dionizio, D. (2017). Aplicativo multimídia "Safe Bathing" em plataforma móvel como tecnologia para o cuidado à beira leito de pacientes infartados: construção e validação. [dissertação]. Universidade Federal Fluminense, Escola de Enfermagem Aurora Afonso Costa.

Ferreira, J. L. (2020). Cultura digital e formação de professores: uma análise a partir da perspectiva dos discentes da licenciatura em pedagogia. Educar em Revista, 36, e75857.

Gil, A. C. (2007). Como elaborar projetos de pesquisa. (4a ed.), Atlas.

Gomes, M. L., Rodrigues, I. R., Moura, N. S., Bezerra, K. C., Lopes, B. B., Teixeira, J. J., et al. (2019). Avaliação de aplicativos móveis para promoção da saúde de gestantes com pré-eclâmpsia. Acta Paulista de Enfermagem, 32(3), 275-281.

Guimarães, M. S. C., Imamura, M. E., Richter, S., \& Monteiro, J. C. S. (2018). Amamentação e tecnologias mHealth: análise dos aplicativos móveis para tablets e smartphones. Revista Eletrônica de Enfermagem, 20.

Mendes, R. M., \& Miskulin, R. G. S. (2017). A análise de conteúdo como uma metodologia. Cadernos de Pesquisa, 47(165), 1044-1066.

Minayo, M. C. S. (2001). Ciência, técnica e arte: o desafio da pesquisa social. In: Minayo, M. C. S, organizadora. Pesquisa social: teoria, método e criatividade. Vozes.

Minayo, M. C. S. (2014). O desafio do conhecimento: pesquisa qualitativa em saúde. (14a ed.), Hucitec Editora.

Pope, C., \& Mays, N. (2005). Pesquisa qualitativa na atenção à saúde. (2a ed.), Artmed.

Silveira, M. S., \& Cogo, A. L. P. (2017). Contribuições das tecnologias educacionais digitais no ensino de habilidades de enfermagem: revisão integrativa. Revista Gaúcha de Enfermagem, 38(2), e66204.

Sousa, C. S., \&Turrini, R. N. T. (2019). Desenvolvimento de aplicativo de celular educativo para pacientes submetidos à cirurgia ortognática. Revista LatinoAmericana de Enfermagem, 27, e3143.

Sousa, J. R., \& Santos, S. C. M. (2020). Análise de conteúdo em pesquisa qualitativa: modo de pensar e de fazer. Pesquisa e Debate em Educação, 10(2), $1396-1416$. 